\title{
AIDS, Other Minorities
}

National Cancer Institute

\section{Source}

National Cancer Institute. AIDS, Other Minorities. NCI Thesaurus. Code C18627.

AIDS related research with a minimum of $20 \%$ (or $\$ 100,000)$ relevance to individuals who are Asian/Pacific Islanders or Native Americans, including American Indians, Alaskan Natives, and Hawaiian Natives. 